\title{
A Universidade de Évora e a psicogênese da socie- dade portuguesa em tempos de reforma católica
}

\author{
Cíntia Mara Bogo Bortolossi \\ Célio Juvenal Costa \\ Universidade Estadual de Maringá (Brasil)
}

\section{Resumo}

O artigo tem o objetivo de relacionar o curso de Teologia Moral, existente na Universidade de Évora no século XVI, com o processo de formação da sociedade portuguesa no respectivo período. O curso de Teologia Moral, também chamado de Casos de Consciência, era designado à formação do clero diocesano e, portanto, destinado à preparação de religiosos que iriam trabalhar nas paróquias junto aos seus fiéis. A pesquisa possui uma abordagem qualitativa e é do tipo documental e bibliográfica. A teoria dos processos civilizatórios de Norbert Elias serviu de suporte para a análise aqui realizada, possibilitando um diálogo com a sociedade e a leitura de uma determinada realidade. Por meio de nossa análise, pudemos identificar que a instituição superior, administrada pela Companhia de Jesus, desempenhou o papel de construção da psicogênese daquela sociedade por meio da formação dos religiosos que precisavam conhecer as regras morais da lgreja para a devida orientação de seus seguidores.

Palavras-chave: Companhia de Jesus. Universidade de Évora. Reforma católica. Curso de Teologia Moral.

\section{The University of Évora and the psychogenesis of Portuguese society in times of Catholic reform}

\begin{abstract}
The article aims to relate the course of Moral Theology, existing at the University of Évora in the 16th century, with the Portuguese society formation process of in the respective period. The Moral Theology course, also called Cases of Conscience, was designed to the formation of the diocesan clergy and, therefore, intended to prepare religious who would work in parishes with their faithful. The research has a qualitative approach and is documentary and bibliographical. Norbert Elias' theory of civilizing processes served as support for the analysis carried out here, enabling a dialogue with society and the reading of a given reality. Through our analysis, we were able to identify that the higher institution, administered by the Companhia de Jesus (Society of Jesus), played the role of construction of the psychogenesis of that society through the formation of religious who needed to know the Church's moral rules for the proper guidance of their followers. Keywords: Society of Jesus. Évora University. Catholic reform. Moral Theology course.
\end{abstract}


A Universidade de Évora e a psicogênese da sociedade portuguesa em tempos de reforma católica

\section{La Universidad de Évora y la psicogénesis de la sociedad portu- guesa en tiempos de reforma católica}

\section{Resumen}

El artículo tiene como objetivo relacionar el curso de Teología Moral, existente en la Universidad de Évora en el siglo XVI, con el proceso de formación de la sociedad portuguesa en el respectivo período. El curso de Teología Moral, también llamado Casos de Conciencia, estaba destinado a la formación del clero diocesano y, por lo tanto, a la preparación de los religiosos que trabajarían en las parroquias con sus fieles. La investigación tiene un enfoque cualitativo y es documental y bibliográfica. La teoría de los procesos civilizadores de Norbert Elias sirvió de soporte al análisis aquí realizado, posibilitando el diálogo con la sociedad y la lectura de una determinada realidad. A través de nuestro análisis, pudimos identificar que esta institución superior, administrada por la Compañía de Jesús, desempeñó el papel de construcción de la psicogénesis de esa sociedad a través de la formación de religiosos que necesitaban conocer las reglas morales de la lglesia para la adecuada orientación de sus seguidores.

Palabras clave: Compañía de Jesús. Universidad de Évora. Reforma católica. Curso de Teología moral.

\section{Introdução}

Psicogênese e Sociogênese são conceitos elaborados pelo teórico alemão Norbert Elias, que permitem a leitura de uma determinada sociedade. A Sociogênese se refere a uma mudança social a longo prazo, porém, só pode ser entendida se analisada juntamente à Psicogênese. Isto porque, para Elias (1994a), uma mudança na estrutura da sociedade não ocorre sem uma mudança no comportamento individual dos integrantes da figuração social. Por conseguinte, a teoria de Elias aponta para a união entre indivíduo e sociedade, e a importância de se conhecer o processo histórico de duas formas: o psicogenético e sociogenético. As mudanças de uma sociedade são acompanhadas pela mudança de comportamentos individuais, "[...] isto porque as estruturas da personalidade e da sociedade evolvem em uma inter-relação indissolúvel" (ELIAS, 1994a, p. 221). Por conseguinte, o objetivo aqui é relacionar a Universidade de Évora do século XVI com o processo psicogenético de formação da sociedade portuguesa no período.

A universidade eborense fora edificada no ano de 1559. Entre os seus objetivos estava a formação do clero diocesano por meio do curso de Teologia Moral existente em seu currículo. Essa capacitação era urgente, pois, como 
verificamos em Dias (1960), tem-se uma crise moral e intelectual que se instaurava na lgreja Romana no respectivo período. O Concílio de Trento (1545 a 1563) é convocado e realizado como resposta a esse contexto em busca de uma reforma da religião. Uma das decisões de suas sessões foi a importância do fortalecimento do clero diocesano. Também coloca sob a responsabilidade dos bispos o dever de aumentar o número de sacerdotes, "[... . para o emprego de adminiftrar os Sacramentos, e celebra o Culto divino, em todas as Igrejas Parochiaes ou Baptifmaes" (REYCEND, 1781, p. 65). Conforme Coelho (2016), - Cardeal Dom Henrique, irmão do rei D. João III, fora o precursor das reformas da lgreja em Portugal, após o Concílio de Trento.

A Universidade de Évora também foi a primeira instituição superior administrada pela Companhia de Jesus em Portugal. Ela é fruto do empenho do Cardeal D. Henrique (arcebispo de Évora de 1540 a 1564), que, em tempos de Concílio de Trento, estava preocupado com a formação do clero de sua diocese.

\section{A Teologia Moral na Universidade de Évora}

Os cursos de Humanidades, Artes e Teologia compunham o currículo da instituição, estipulado em seus estatutos. $\bigcirc$ curso de Humanidades, conforme Dias (2009), era composto por Latim, Grego, Hebraico e Gramática Latina. Já o curso de Artes, referia-se aos estudos de Filosofia, e era considerado um preparatório para o estágio seguinte, ou seja, o curso de Teologia.

$\bigcirc$ curso de Teologia Moral (ou Casos de Consciência), existente no currículo da Universidade de Évora, era o diferencial da instituição no século XVI, haja vista que o respectivo curso não existia no currículo da Universidade de Coimbra. Segundo Dias (1960, p. 440), o curso de Teologia de Coimbra era diferente do de Évora, pois não existia no plano de estudos de Coimbra a Teologia Moral e, assim, não era destinado à "[...] formação de curas de almas". Para o autor, o objetivo do curso de Coimbra era a formação de teólogos e, especialmente, de teólogos das corporações regulares.

Serafim Leite (1949), em sua História da Companhia de Jesus no Brasil, ao analisar os estabelecimentos de ensino jesuíticos no Brasil, nos esclarece a respeito do que seria o curso de Teologia Moral, ou Casos de Consciência. Conforme o autor, a Teologia Especulativa ou Dogmática estava acima dos 
A Universidade de Évora e a psicogênese da sociedade portuguesa em tempos de reforma católica

demais estudos existentes na Companhia de Jesus, como o autor pontua, "[...] é o mais alto curso" (LEITE, 1949, p. 175). Nesses estudos, só eram admitidos alunos acima da média, existindo, assim, uma seleção para a aceitação dos estudantes.

Assim, no curso de Teologia existiam dois níveis de estudos. Um primeiro chamado de curso breve, em que os alunos estudavam apenas os dois primeiros anos, e o curso longo, composto por mais dois anos. Realizavam os dois últimos anos da Teologia apenas os estudantes considerados com "talento insigne", ou seja, os que eram alunos notáveis e que tinham elevado grau e talento promissor para pregar ou governar. Assim, "[...] dos que estudavam só até $02^{\circ}$ ano de Teologia, por se insistir mais na Teologia Moral ou Casos de Consciência, saíam os Coadjutores Espirituais [...]" (LEITE, 1949, p. 175), os chamados padres casuístas.

Ratio Studiorum, usado nos colégios e universidade dos jesuítas estabelece as regras relacionadas aos professores de Casos de Consciência a fim de direcionar as práticas educativas nos dois primeiros séculos de existência da ordem. O objetivo era consagrar "[...] todos os seus esforços, toda a sua habilidade em formar bons párocos ou administradores dos Sacramentos" (RATIO STUDIORUM, 1952, p. 97).

Conforme Demmer (1999), a Teologia Moral após o Concílio de Trento, estava a serviço da formação de sacerdotes "[...] que cuidam das almas" (DEMMER, 1999, p. 26). Por conseguinte, foram escritas obras utilizadas nas aulas dessa disciplina que trabalhava com as questões e indagações do momento.

A moral no século XVI era uma moral casuística: "[...] examinou os vários problemas ou casos que poderiam interessar os confessores na recta administração do sacramento da penitência, segundo a disciplina estabelecida no Concílio de Trento" (SILVA, 1971, p. 267). A partir de então, multiplicaram-se as Sumas e os Compêndios de Teologia Moral.

Para Araújo (2007), os manuais elaborados buscam atender às exigências do Concílio de Trento com conteúdos relacionados à administração do sacramento da Penitência. O autor pontua que após Trento a lgreja se esforçou e se organizou para formar confessores, formando seminários, cursos de Casos de Consciência e incentivando a elaboração de manuais de Teologia Moral. 
A moral dos manuais, do período entre os séculos XVIl e XX, repousa sobre quatro pilares: o ato humano livre, a lei, a consciência e o pecado, sustentados pelos Mandamentos da lei de Deus e da Igreja. Os moralistas se ocupam, dentre os atos humanos que thes interessam, sobretudo com o tema do pecado (ARAÚjO, 2007, p.

105).

Para o autor, aos jesuítas fora confiada essa missão, a de formação dos confessores. E para essa formação, se utilizavam destes manuais que forneciam regras de comportamento, colocando interrogações e respostas para inúmeras situações cotidianas, estabelecendo o que era considerado desde um pecado simples a um pecado mortal.

Teologia Moral era o que diferenciava a Universidade eborense no século XVI, assim, buscamos compreender qual era o ideal de formação do indivíduo no curso de Teologia. O que seria, portanto, esse curso de Teologia Moral existente na Universidade de Évora? Para responder a questão, recorremos a um documento do século XVII, de autoria do padre jesuíta Hermann Busenbaum, intitulado Meddulla da teologia moral, aonde se resolvem com fácil \& perspicaz methodo os casos de consciência. Tirados de vários \& aprovados autores. $\bigcirc$ entendimento da Teologia Moral do século XVII refere-se, também, ao que se entendia no século XVI.

Conforme Araújo (2007), os moralistas se ocupavam especialmente da temática do pecado. E é bem essa postura que conseguimos identificar na leitura do documento escrito por Hermann Busenbaum.

\section{Manual de Teologia Moral}

O manual de Teologia Moral do padre Hermann Busenbaum fornece regras de comportamento por meio de perguntas e respostas para inúmeras situações cotidianas, estabelecendo o que era certo do ponto de vista da Igreja, o que era considerado desde um pecado simples a um pecado mortal e, com isso, estabelece regras para o viver.

repertório completo de padrões sociais de auto-regulação que o indivíduo tem que desenvolver dentro de si, ao crescer e se transformar num indivíduo único, é específico de cada geração e, por 
A Universidade de Évora e a psicogênese da sociedade portuguesa em tempos de reforma católica

conseguinte, num sentido mais amplo, específico de cada sociedade (ELIAS, 1994c, p. 9).

Ao se estabelecer um manual de comportamento, consequentemente se estabelecem regras de vivência em sociedade. Tais regras passaram a ser aceitas como um modelo que deveria ser compreendido como o correto, um padrão, e tornou-se, assim, uma característica dessa geração, desse período pós Concílio de Trento e Reforma Católica.

O documento Medulla da Theologia Moral [...], de 1683, logo em suas primeiras páginas, esclarece que as respostas aos Casos de Consciência foram retiradas de diversos autores, porém, a autoria da obra é do padre Hermann Busembau, integrante da Companhia de Jesus e licenciado em Teologia. A obra é dividida em livros com discussões variadas e bem fundamentadas acerca das regras que deveriam regular os atos humanos, o que os fiéis deveriam crer e a virtude moral da religião. Também discute em questões relacionadas aos tipos de pecado, aos sacramentos e às censuras eclesiásticas.

$\bigcirc$ primeiro livro nos apresenta discussões sobre as regras dos atos humanos, de modelos que deveriam regular as ações dos indivíduos. Tais pre6 ceitos deveriam ser internalizados e o indivíduo passaria a ter consciência sobre suas ações. Uma das perguntas é justamente essa: $\bigcirc$ que é afinal consciência? "Que Confciencia he hum dictame da razão, ou hu acto de Entendimento, com que julgamos que [...] fe deve fazer alguma coufa por boa, ou fe deve deyxar por má [...]" (BUSENBAUM, 1683, p. 1). É, portanto, a consciência que irá fazer com que o indivíduo tenha uma boa ação por meio do uso da razão. Conforme o autor, a consciência geralmente é boa, "recta", porém, às vezes pode se mostrar em direção contrária, indo no caminho dos erros, mas, tal caminho para o erro pode, segundo o autor, ser evitado. Por conseguinte, pontua que é preciso agir para que as pessoas sigam a "Consciencia recta", pois ela representa uma regra "[...] derivada da primeyra, e principal regra de todas as acções humanas, qual he a Divina e Eterna ley" (BUSENBAUM, 1683, p. 2).

A característica de controle individual das ações, segundo Elias (1 994b), é um processo civilizador individual, que ocorre quando o indivíduo passa a manter um autocontrole de suas emoções, devido a não estar mais isolado, mas, sim, vivendo em uma nova estrutura social, interligado com o outro. 
A aprendizagem dos autocontroles, chame-se eles de 'razão', "consciência", 'ego' ou 'superego', e a consequente moderação dos impulsos e emoções mais animalescas, em suma, a civilização do ser humano jovem, jamais é um processo inteiramente indolor, e sempre deixa cicatrizes (ELIAS, 1994b, p. 205).

[...]

Todo homem, por assim dizer, enfrenta a si mesmo. Ele 'disfarça as paixões', 'rejeita o que quer o coração" e 'age contra seus sentimentos'. O prazer ou a inclinação do momento são contidos pela previsão de consequências desagradáveis, se forem atendidos (ELIAS, 1994b, p. 227).

Os sentimentos do momento são reprimidos, pois passa-se a pensar nas consequências posteriores. É o medo das consequências que passa a polir os comportamentos e, consequentemente, muda as relações sociais e interpessoais. A partir do momento em que o documento orienta que o indivíduo deve ter consciência de suas ações, significa que, pelo uso da razão, deve procurar atitudes corretas, o autocontrole, rejeitar o que poderia posteriormente causar consequências negativas perante uma sociedade que se caracteriza como essencialmente religiosa.

[...] o código de conduta mais sofisticado e o maior grau de autocontrole costumam associar-se a um grau mais elevado de disciplina, circunspecção, previdência e coesão grupal. Isso oferece recompensas sob a forma de status e poder, para contrabalancear a frustação das limitações impostas e da relativa perda de espontaneidade (ELIAS; SCOTSON, 2000, p. 171).

Todo autocontrole poderia gerar frustações nos indivíduos, com isso, o que os motivava a seguir esse padrão de comportamento era muitas vezes o status, a recompensa por pertencer a um grupo de poder. Desrespeitar as regras naquele contexto também significava um sinal de inferioridade social.

Uma das recomendações e/ou orientações evidenciadas no manual de Teologia Moral é a importância atribuída às participações dos indivíduos na missa, encarada como um fator essencial para se evitar o pecado. Assim, aquele que faltava a uma cerimônia religiosa ficava mais vulnerável aos pecados. A única falta justificada era o atendimento aos enfermos. "[...] menos mal he deyxar a Miffa, do que defamparar ao enfermo; porque o preceito da Miffa 
A Universidade de Évora e a psicogênese da sociedade portuguesa em tempos de reforma católica

he affirmativo e de direito humano e do enfermo he negativo e de direyto natural [... ]" (BUSENBAUM, 1683, p. 4).

Na sequência, o manual esclarece acerca dos conceitos preceito e lei. Preceito, no respectivo período, vinha antes da lei. Enquanto uma comunidade não recebia as devidas orientações de um superior em forma de lei, referia-se, então, a um preceito, que poderia ser natural ou positivo. $\bigcirc$ preceito natural referia-se à nossa razão (consciência), entre o que se deve fazer ou evitar. Já o preceito positivo seria o que se impõe "[...] pela vontade livre de Deos e dos homens, e depende dela o preceyto do Baptismo, do jejum Quadragefimal, etc." (BUSENBAUM, 1683, p. 12). Por conseguinte, os preceitos positivos poderiam sofrer alterações ao longo do tempo, já os naturais, não, estes permaneciam. Os preceitos positivos eram compostos pelos preceitos de direito divino (concedido por Deus) e preceito de direito humano (imposto pelos homens). "O preceyto pofitivo humano fe divide em preceyto de direyto Ecclefiaftico, ou canônico, que he o que fe propõem com autoridade da Igreja, ou pelo Summo Pontifice, ou pelo Concílio [...]" (BUSENBAUM, 1683, p. 12-13). Com essa diferenciação entre os conceitos, o documento reforça que ninguém estava obrigado a cumprir a lei até que ela fosse promulgada.

É importante mencionar que a lei positiva era imposta e não dependia da aceitação da comunidade.

Com tudo a fentença mais verdadeira he a dos Theologos que a leys do Magiftrado abfoluto não dependem da aceitação e confentimento do Povo, mas que em fe promulgando legitimamente, obrigaõ ao povo a que as admitta, principaliffimamente, que não tem o feu poder do povo, fenaõ de Chrifto (BUSENBAUM, 1683, p. 13).

Por conseguinte, as leis da Igreja deveriam ser respeitadas pela comunidade, afinal, elas se referiam a uma lei maior, que era a lei de Deus. Consequentemente, as decisões promulgadas pelo papa deveriam ser obedecidas, uma vez que ele representava a lei divina. $\bigcirc$ mesmo deveria ocorrer com as decisões dos concílios. Tais leis precisavam chegar até o povo, isto porque, quem não seguia uma lei da lgreja pecava gravemente.

Podemos afirmar que suas linhas possuem orientações relacionadas aos comportamentos, estabelecendo o que era ou não permitido. Como o próprio nome sugere, questões de Casos de Consciência, do uso da razão. 
Temáticas como o consumo de carne, a participação nas missas, os jejuns, a quaresma, os casos de incesto e os pecados do adultério. "Se o cafado comette adultério com cafada, ha dous peccados de injuftiça, hum contra fua própria molher; outro contra o marido da adultera, como tão bem fe hû com mefma acção mataffe dous, fão dous homicídios [...]" (BUSENBAUM, 1683, p. 23). Vemos, assim, que o pecado do adultério, por exemplo tinha a gravidade de um assassinato, conforme a Teologia Moral do período.

Na sequência, a Medulla aponta para os casos em que o Confessor poderia absolver o penitente. Um dos motivos que poderiam ocasionar a absolvição de um penitente era a negligência, o desconhecimento da regra. Com isso, o manual menciona que é obrigação do pároco instruir suas ovelhas, seus fiéis, em relação aos atos considerados pecados mortais. "E fe defpois fe thes propõem fufficientemete a noffa Fé, eftão obrigados a abraçalla" (BUSENBAUM, 1683, p. 36). Aí está a importância de fazer chegar até os fiéis os preceitos da lei divina. Para isso, deveriam se valer do trabalho dos bispos, dos párocos, e de outros, afinal, era preciso conhecer as normas para que as pessoas não justificassem seus atos alegando desconhecimento.

Duas coisas que causavam medo entre os portugueses no século XVI: as consequências do pecado mortal e da excomunhão. Ambos eram sinônimos de exclusão. Uma era exclusão do reino de Deus e a outra, uma exclusão social. Assim, ambas penalidades eram usadas como meio de se controlar os comportamentos.

Para Norbert Elias (1994a), o medo pode desempenhar um papel substancial como um mecanismo de processo civilizador, pois tal sentimento é internalizado no indivíduo que passa a controlar seus impulsos de forma inconsciente. É o medo das consequências que passa a polir os comportamentos e, consequentemente, muda as relações sociais e interpessoais.

A Medulla de Teologia Moral também exemplifica situações de pecados e suas respectivas penalidades. Por exemplo, caso uma mulher se vestisse com roupas de homem sem intenção, o comportamento se enquadrava como pecado venial. Entretanto, caso o fizesse propositalmente, o pecado passava a ser mortal. A questão da veste/ornamentos que a mulher poderia usar é bem debatida no documento. Assim, discute-se as situações em que as atitudes se enquadravam como pecado venial ou mortal. 
Oterceiro livro da Medulla de Teologia Moral aborda os preceitos do Decálogo da Igreja. Logo em seu início, reflete sobre a virtude moral da religião. Entendemos que na concepção de Teologia Moral presente no documento, tanto os aspectos interiores como os exteriores deviam ser voltados a Deus. "O feu acto interior he, a fubmiffaõ da alma, com que veneramos a infinita excellencia de Deos. $O$ exterior, he aquelle, com que declaramos o interior, como a ração, o facrificio" (BUSENBAUM, 1683, p. 66). Assim, o comportamento exterior de submissão deveria refletir o interior.

Os sonhos e adivinhações são abordados no terceiro livro. Não eram proibidos, apenas as previsões relacionadas à natureza, pois eram encaradas como importantes para a agricultura. $\bigcirc$ livro cita os ciganos e o pecado de quem os consultava. Condena a idolatria, considerada pecado mortal. Também menciona e condena as orações das feiticeiras e as simpatias, que fiéis procuravam, especialmente as que na época eram feitas para se casar "[...] por no dia de S. Mathias folhas de hera fobre a agoa para conhecer com quem fe hão de cafar" (BUSENBAUM, 1683, p. 73).

Outra questão presente no documento refere-se às obrigações de filhos com os pais e de pais com os filhos. Até a questão da amamentação materna é levantada: "[...] que a Mãy tem obrigação (porem de peccado venial) de criar a feus peitos cõ feu próprio leite os filhos, fe naõ tiver jufta efcufa; então eftá obrigada sob peccado grave a bufcarlhe boa ama" (BUSENBAUM, 1683, p. 125). Entende-se que este sustento da criança com o leite materno era indicado até os três anos, na sequência, o alimento da criança passava a ser responsabilidade do pai.

As obrigações dos casados também são mencionadas nessa parte do documento. As regras estão relacionadas às decisões acertadas no Concilio de Trento. Por conseguinte, descrevem situações consideradas pecados tanto no comportamento da mulher como do homem.

Que pecca gravemente o marido. Se diz a molher palavras de ignominia ou infâmia. Se the põem eftorvo fem caufa jufta para que guarde os preceitos de Deos e da lgreja; Se porem o eftorvo, que the põem he em ordem a coufas que fão fó de confelho, como confeffar, comungar, e então ainda q não tenha caufa, fó peca venialmente [...] (BUSENBAUM, 1683, p. 130). 
Assim, como o homem tinha suas obrigações para com a mulher, a mulher também deveria exercer o seu da forma indicada. Percebe-se que um detalhe poderia mudar o pecado de venial para mortal.

Em relação aos contratos, é nítida no documento a condenação que se fazia da prática da usura. "O ufuario publico, ou notório não fe deve admittir à communhão, nem abfolto athé que reftitua as ufuras, nem deve fer enterrado em fagrado, e o que fabendo-o o enterra fica excommungado" (BUSENBAUM, 1683, p. 193). Tal citação nos mostra o quanto a transgressão das regras impostas pela lgreja tinha consequências não apenas na relação indivíduo-Deus, mas também na relação individuo-sociedade, pois não participar da comunhão ou não ser enterrado em um cemitério, era tornar público o comportamento incorreto para com a lgreja, acarretando a exclusão social do indivíduo e até mesmo da família.

Ao partir para o quarto livro, tem-se toda uma fundamentação sobre os preceitos particulares próprios do estado do homem. Inicia afirmando que além dos fiéis serem obrigados a ter conhecimento dos mandamentos da Igreja, sob pena de pecado mortal, deveria o homem também saber as regras que pertencem a seu estado, a seu ofício. Assim, após apresentar preceitos e regras comuns a todos, o documento passa a "[...] tratar dos que pertencem ao eftado próprio de cada hum em particular" (BUSENBAUM, 1683, p. 245).

Assim, o quarto livro apresenta o que seria o estado religioso. Qual a natureza desse estado? É um modo estável para se viver conforme a Igreja como fiéis "[...] à perfeyçaõ do amor divino fazendo votos de perpetua Probrefa, Caftidade e Obediencia" (BUSENBAUM, 1683, p. 245). Desse modo, especifica-se as condições para a profissão de um religioso. Tal escolha deveria ser livre, e não uma atitude tomada por violência ou constrangimento. A preocupação com a moral do religioso é evidente no documento.

Que eftá obrigado o Religioso por força da fua profiffão a dar algus progreffos no caminho da perfeição; porq por rafaõ defta eftá obrigado a guardar o feu estado; o qual he de perfeiçaõ, ou dos q fe dirigem a ella [...] porq ifto he intrinfecamente querer dirigir o caminho à perfeição (BUSENBAUM, 1683, p. 248).

religioso, pelo seu estado, tinha a obrigação de buscar constantemente um estado de perfeição. Essa preocupação exigida está relacionada ao tipo de religioso que se desejava formar naquele momento. Faz parte desse 
A Universidade de Évora e a psicogênese da sociedade portuguesa em tempos de reforma católica

estado almejado, a obediência às regras da lgreja, tanto que o documento pontua que se o religioso desprezasse tais regras, estaria em estado de pecado mortal. "O Religiofo da Companhia de lefus peccará mortalmente fenaõ põem todo o cuidado em evitar as faltas e defeitos, pelos quaes prevé o defpedirão [...]" (BUSENBAUM, 1683, p. 249).

Um religioso poderia ser expulso se tivesse cometido algo considerado grave, ou seja, quando havia uma causa justa para isso. Tal dano não deveria ser tolerado, pois era considerado um ato muito grave para a religião. Isso muda com o papa Urbano VIII, no ano de 1624, e a orientação passa a ser que deveriam ser expulsos apenas os religiosos que tinham cometido atos que eram "incorrectiveis" (BUSENBAUM, 1683).

Na sequência da Medulla de Teologia, temos o quinto livro, que discorre sobres questões relacionadas aos pecados. A discussão inicia-se com a interrogação: $O$ que é pecado? "Que o peccado fe define: Tranfgreffão da ley ou voluntario receffo da divina regra" (BUSENBAUM, 1683, p. 311 ). As regras eram, assim, estabelecidas pela lei divina, e, por isso, deveriam ser aceitas por todos. $\bigcirc$ transgressor deveria necessariamente ter o conhecimento da lei divina para considerar um pecado como ato voluntário. Assim, o documento 12 tece considerações sobre situações que são ou não pecado, da mesma forma que apresenta as diversas situações consideradas pecados mortais e veniais. Nas discussões sobre o pecado, o documento ainda reforça a importância do controle dos impulsos.

Sobre o controle individual dos impulsos, Elias (2006, p. 21) mostra que os seres humanos não nascem com uma predisposição a regular suas punções; o fazem apenas mediante o aprendizado do respectivo controle. "O processo universal de civilização individual pertence tanto às condições da individualização do ser humano singular como às condições da vida social em comum dos seres humanos." Para o autor, o processo de civilização está relacionado ao de autorregulação. "Sem ela, as pessoas ficariam irremediavelmente sujeitas aos altos e baixos das próprias pulsões (ELIAS, 2006, p. 36).

Na sequência da Medulla tem-se, no quinto livro, explicações sobre o que era considerado pecado mortal e o que era considerado pecado venial. O pecado mortal era um ato considerado grave, que "[... priva ao homem da amifade, e graça de Deos". Um ato que merecia uma pena eterna, pois afastava o indivíduo de Deus. "Chamafe mortal; porque priva da graça habitual, 
que he principio da vida efpiritual da alma, a qual fe occafiona daqui fua efpiritual morte" (BUSENBAUM, 1683, p. 321). Os pecados cometidos contra as virtudes teológicas eram considerados mortais porque ofendiam diretamente a Deus.

Diferentemente, o pecado venial não privava totalmente a amizade entre o indivíduo e Deus, apenas "[...] diminue o fervor da caridade, pelo merece pena temporal" (BUSENBAUM, 1683, p. 321). Tal pecado não causava a morte espiritual do indivíduo, pois, como o termo sugere, referia-se a um pecado perdoável.

Ao mencionar os pecados capitais, o documento descreve várias situações e indica qual era o pecado e a sentença. Vamos exemplificar a questão do segredo. Se alguém revelasse o segredo de alguém, o texto indicava a uma traição, o que era considerado um pecado mortal. Porém, se o indivíduo escutar o segredo e perceber que tal situação poderia ser danosa ou causar discórdia, e decidir por revelá-lo, aí, nesse caso, refere-se a um pecado venial. "[...] ou abrindo e lendo cartas alheyas e fe só as ler por faber os fegredos de outro, he coriofidade; porem fe he em coufa grave, de fi ferá mortal" (BUSENBAUM, 1683, p. 330).

Ao mencionar a situação de pecado relacionada à embriaguez, o documento cita que este era um estado de não uso das razões e, assim, considerado um pecado mortal. Entretanto, conforme o documento, "[...] não he peccado a ebriedade, quando os Medicos dizem, que naõ fe pode recuperar a faude fenaõ por efte meyo" (BUSENBAUM, 1683, p. 336). Vejamos o quanto suas orientações guiavam a sociedade.

$\bigcirc$ livro sexto, por sua vez, trabalha sobre questões referentes aos sacramentos (Batismo, Confirmação, Eucaristia, Penitência, Extrema Unção, Ordem e Matrimônio). No início, esclarece o conceito de sacramento. "Que he huã coufa fenfivel, que por eftavel inftituição de Chrifto tem força de fantificar e de caufar a graça juftificante e por confeguinte, de a fignificar" (BUSENBAUM, 1683, p. 3411. Ou seja, os sacramentos foram instituídos para o indivíduo alcançar a denominada graça, ou então, um estado com Deus. Dessa forma, deveriam ser vistos como um auxílio do indivíduo na busca pela santidade. Assim como o documento do Concílio de Trento, a Medulla da Teologia Moral reforça as questões dos sacramentos que passaram a ser resgatadas pela lgreja. 
A Universidade de Évora e a psicogênese da sociedade portuguesa em tempos de reforma católica

No documento, percebe-se que a função do pároco é valorizada e encarada como importante, pois era ele quem iria ministrar os sacramentos da Igreja. $\bigcirc$ livro prega que "[...] a razão he; porque dos Paftores propriamente he apafcentar fuas ovelhas, o q fe faz pelos Sacramentos" (BUSENBAUM, 1683, p. 3811. Era o pároco o responsável pela extrema unção, pela eucaristia e pelos matrimônios. Apenas quando o pároco não podia levar até um enfermo a eucaristia, um outro sacerdote (secular ou regular) o poderia substituir.

Aquele sobre o qual pairava a desconfiança de estar em pecado mortal não deveria receber a eucaristia antes de se confessar. Isto porque, a eucaristia removia apenas os pecados veniais. "Que o que duvida fe peccou mortalmente, ou duvida fe confeffou dividamente o peccado mortal, deve antes da comunhão confeffar-fe" (BUSENBAUM, 1683, p. 388).

Para o confessor poder absolver as transgressões, deveria entender todos os pecados do penitente, tornando-se essencial um estudo aprofundado dos tratados de Teologia Moral. Para estabelecer o que era uma sentença, naquele período, ele deveria saber dos comportamentos que resultavam em pecado mortal e venial, em casos de excomunhão, em censuras, dentre outros. Caso ele absolvesse alguém sem o devido conhecimento de determinado 14 pecado, quem estaria pecando gravemente seria o próprio confessor. "Que o Confeffor, que abfolve por ignorância ao que não podia abfolver, pecca de dous modos, a faber, ignorando o q pertence a feu officio e abfolvendo indevidamente" (BUSENBAUM, 1683, p. 456). Por isso, a importância de uma boa formação, de estudar e conhecer os pecados e suas consequências.

Assim como o que fora discutido no Concílio de Trento, o documento também tece considerações acerca do matrimônio. Estabelece, por exemplo, que o casamento deveria ser realizado na igreja pelo próprio pároco, ou por alguém que recebia a licença para tal procedimento. Não existia um momento específico para o sacramento da forma como conhecemos na atualidade, ele era, assim, realizado em um momento da missa.

Ao partir do princípio de que tal documento pode ser visto como um código de leis, este refere-se ao Concílio de Trento como direito novo (leis novas) para esclarecer dúvidas sobre o casamento entre pessoas com parentesco.

E antes do Tridentino por direito antigo dirimia efte impedimento o matrimonio entre o efpofo, e confanguineos da efposa até $O$ quarto grão, e refultava de quaefquer efpofaes, ainda que foffem 
inválidos, como não foffem por falta de confentimento. Porém agora por direito novo do Tridentino não refulta de efpofaes inválidos e somente irrita o matrimonio até o primeiro gráo, quando nafce das efponfaes: até o quarto quando nafce de matrimonio rato [ratificado] (BUSENBAUM, 1683, p. 502).

Ou seja, os concílios eram vistos como verdadeiros códigos de lei que deveriam ser aplicados nos locais em que a cultura fosse católica. Seguindo as definições de Trento, o documento condena e anula os casamentos que foram realizados de forma clandestina. Para um casamento ser considerado válido pela lgreja, deveria ser realizado diante de um pároco, ou outro sacerdote, na presença de duas testemunhas. Antes do casamento, também era função do pároco fazer uma inquirição sobre o estado em que se encontrava os que desejavam receber o sacramento.

A excomunhão nesse período, também significava uma exclusão social que não se finalizava na ocasião da morte, pois até mesmo nesse momento era evidenciado a toda a comunidade que aquele indivíduo teve um comportamento incorreto do ponto de vista religioso. Se um indivíduo tivesse sido excomungado em vida, não poderia ser sepultado em um cemitério cristão.

Ao não tolerado fe priva de fepultura Ecclefiaftica, para que não poffa fer enterrado em lugar fagrado e bento, e fazendofe o contrario, fe fe puderem conhecer os cadáveres, deve fer defenterrado, nem podem celebrarfe os Divinos Officios naquelle lugar, fem fer novamente reconciliado (BUSENBAUM, 1683, p. 524).

sepultamento apenas era permitido se algum religioso absolvesse o indivíduo de sua pena, de sua excomunhão, no momento da morte.

capítulo dois do respectivo livro esclarece as dúvidas relacionadas à excomunhão.

Que a Excommunhaõ he cenfura, pela qual fica hum privado da Communhaõ da lgreja, e he de dous modos: Menor que fomente priva do ufo paffivo dos Sacramentos, ifto he de os receber: e mayor, que também fe chama Anathema, e he a que quafi fempre fe entende por nome de excomunhão Eclefiáftica [...] (BUSENBAUM, 1683, p. 5191. 
A Universidade de Évora e a psicogênese da sociedade portuguesa em tempos de reforma católica

Anátema, conforme o dicionário, significa uma pena grave, uma expulsão do convívio em sociedade, quase que uma maldição. $\bigcirc$ documento ressalta que a condenação deveria ocorrer de forma pública, pois os católicos deveriam ter a informação para poder evitar o contato com os expulsos. texto afirma que, quando isso não fosse possível, que se adotasse outros meios de se comunicar aos católicos os nomes dos indivíduos que receberam tal pena.

Essa informação deveria existir, pois aquele que se comunicava e se relacionava com um excomungado nessa época, também poderia receber tal pena. "Que quando o direito diz, que o que communica com o excommungado incorre femelhante excommunhão [...]" (BUSENBAUM, 1683, p. 520). Quando o excomungado era um religioso, não poderia mais administrar os sacramentos da lgreja, perdendo também o direito de realizar seus demais ofícios religiosos.

A excomunhão enquanto penalidade também trazia outros prejuízos para a vida do indivíduo. Com a penalidade, ele não poderia assumir funções como juiz, advogado, procurador, testemunha, dentre outros. "O excommungado não tolerado, fica privado do ufo da jurifdicção; pelo que não pode validamente eleger, colar, aprefentar, dar leys, ou fenteça, e o que recebeo defte modo o beneficio do não tolerado, se há de chamar intrufo [...]" (BUSENBAUM, 1683, p. 524). O excomungado ficava, assim, privado de toda uma comunicação civil com os fiéis, pois o contato de um fiel com um renegado era visto como um pecado venial, e poderia ser considerado um pecado mortal dependendo do contato.

A absolvição da excomunhão poderia ser dada pelo bispo ou pelo papa, dependendo do grau de acusação do indivíduo e da pena que ele havia cometido. $\bigcirc$ documento especifica os casos de quando era permitido ao bispo ou ao papa a absolvição da excomunhão.

Finalizando a nossa análise, podemos afirmar que tais manuais e tratados de forma geral, e a Medulla de Teologia Moral em particular, estão diretamente relacionados aos objetivos estabelecidos no Concílio de Trento e ao processo de reforma católica. As sessões do respectivo Concílio colocaram a figura do pároco como essencial para o projeto de reforma, pois era ele quem estaria presente nas igrejas, próximo aos fiéis. Por conseguinte, a formação em Teologia Moral no período era fundamental para que o religioso 
pudesse exercer as suas funções. Assim, o documento analisado pode ser visto como um código de leis, que estabelecia o comportamento desejado, o que era ou não permitido, os tipos de pecados, as penalidades e suas respectivas absolvições.

\section{Considerações Finais}

A Universidade de Évora fora uma instituição formadora dos religiosos em sua fase inicial, realizando um processo de mudança individual que, a longo prazo, traria uma mudança social significativa, especialmente para o objetivo que se pretendia com o processo de reforma católica.

trabalho de formação de párocos e confessores que iriam trabalhar nas igrejas pode ser considerado uma Psicogênese, pois está relacionado aos novos padrões de comportamento que se buscou com o processo de reforma católica. A fim de se reestabelecer o catolicismo em Portugal, o Concílio de Trento definiu a obrigatoriedade da presença dos religiosos em suas igrejas, bem como da formação moral dos párocos como condição para restauração da instituição.

Os manuais de Teologia Moral, utilizados pelos jesuítas na formação do clero diocesano, incentivavam a importância dos sacramentos da lgreja, estabeleciam as regras de comportamento e indicavam as questões acerca do que era considerado desde um pecado simples a um pecado mortal. Os párocos deveriam receber tal formação, pois deveriam orientar seus adeptos em suas igrejas.

A Medulla de Teologia Moral, aqui analisada, pode ser considerada um código de regras, pois existia a interferência da lgreja em todos os aspectos daquela sociedade. Desde um veneno, que poderia ser vendido apenas para um agricultor, até a proibição de atividades em certos dias da semana. Aos dias de festa da lgreja, por exemplo, era proibido toda a obra servil, " [...] que pertencem à matéria externa, e ou fão mecânicas ou illiberaes, cofer, fabricar [...]" (BUSENBAUM, 1683, p. 112).

Ao se estabelecer um manual de comportamento, consequentemente se estabelecem regras de vivência em sociedade. Tais regras passaram a ser aceitas como um modelo, um padrão, tornando-se, assim, uma característica desse período após o Concílio de Trento e Reforma Católica. 
A Universidade de Évora e a psicogênese da sociedade portuguesa em tempos de reforma católica

Regular as ações dos indivíduos refletia, assim, em um processo psicogenético, pois tais preceitos eram trabalhados de forma que o indivíduo internalizasse tais regras e tivessem consciência de suas ações. "Que Confciencia he hum dictame da razão, ou hu acto de Entendimento, com que julgamos que [...] fe deve fazer alguma coufa por boa, ou fe deve deyxar por má [...]" (BUSENBAUM, 1683, p. 1). Assim, é pelo uso da razão que o indivíduo é estimulado a ter consciência de suas ações, do que era considerado pecado e suas respectivas penalidades.

Ocorre, assim, o que o teórico Norbert Elias (1994b) intitulou como processo civilizador individual, que ocorre quando o indivíduo passa a ter um autocontrole de suas ações e emoções. $O$ autocontrole do indivíduo passa a estar presente também na esfera privada, isto porque tais comportamentos passam a ser internalizados, tornando-se parte da sua personalidade. Por isso, existe toda uma relação entre a estrutura social (Sociogênese) e a personalidade dos indivíduos (Psicogênese).

Os sentimentos são reprimidos, pois passa-se a pensar nas consequências posteriores. É o medo das consequências que passa a polir os comportamentos e, consequentemente, muda as relações sociais e interpes18 soais. Para Elias (1994), o medo, enquanto elemento sociogênico, é um dos pilares do processo civilizador.

Todo esse trabalho de formação existente em Évora, especialmente por meio da Teologia Moral, ou Casos de Consciência, objetivava a formação de novos religiosos, necessária no período, que se aproximassem de seus fiéis, da vida em comunidade e que conhecessem as regras morais da lgreja, confessores que iriam orientar seus fiéis quanto ao comportamento para conseguir a salvação. Essa formação, a longo prazo, traria mudanças.

A psicogênese do que constitui o adulto na sociedade civilizada não pode, por isso mesmo, ser compreendida se estudada independentemente da sociogênese de nossa "civilização". Por efeito de uma "lei sociogenética" básica, o indivíduo, em sua curta história, passa mais uma vez através de alguns dos processos que a sociedade experimentou em sua longa história (ELIAS, 1994a, p. 15).

Um movimento na estrutura da sociedade não ocorre sem uma mudança do indivíduo e do comportamento individual. Por isso, a importância 
da formação do clero diocesano, dos padres que iriam trabalhar junto aos fiéis. Eles eram os responsáveis pela formatação individual que se buscava, por isso, sua função fora tão valorizada no Concílio de Trento, visto como um trabalho essencial para a recuperação da lgreja Católica.

A edificação da Universidade de Évora no século XVI, portanto, tem raízes profundas e fortes conexões com a sociedade portuguesa daquele período. Ela está relacionada com a sessões do Concílio de Trento, com o processo de Reforma Católica em Portugal, podendo ser vista como a instituição responsável pela Psicogênese da sociedade portuguesa.

\section{Referências}

ARAÚJO, José Wiliam Corrêa de. A noção de consciência moral em Bernhard Häring e sua contribuição à atual crise de valores. 2007, 365 f. Tese (Doutorado em Teologia) - Departamento de Teologia, Pontifícia Universidade Católica do Rio de Janeiro, 2007. Disponivel em: http://bdtd.ibict.br/vufind/Record/PUC_RIO-1_59d5a3f8ef20465af532 94cfc02137db. Acesso em: 28 mar. 2020.

BUSENBAUM, Hermann. Medulla da theologia moral, aonde se resolvem com facil, \& perspicaz methodo os casos de consciencia. Tirados de varios, \& approvados authores pelo R. P. Herman Busembau... Novamente emmendada, \& tradusida da lingoa latina no portuguez idioma nesta quadragesima septima impressaõ pelo liceciado Manoel Pereira de Sousa... Com hum Trattado no fim, da Bulla da S. Cruzada, \& com as opinioes reprovadas de Alexandre VII. \& Innocencio XI... Lisboa: na officina de Joaõ Galraõ, 1683.

COELHO, Francisco José Senra. O Cardeal-Infante D. Henrique e a reforma tridentina: "Capítulos que por ordenação do Cardeal Dom Henrique foram dados aos prelados" (1563). Concílio de Trento: inovar na tradição. História, Teologia, Projeção. Universidade de Alcalá, 2016.

DEMMER, Klaus. Introdução à Teologia Moral. Tradução Pier Luigi Cabra. Edições Loyola. São Paulo, 1999.

DIAS, José Sebastião da Silva. Correntes de sentimento religioso em Portugal (Séculos XVI a XVIII). Coimbra: Universidade de Coimbra, 1960 (Tomo I).

DIAS, Manuel Madureira. A teologia na Universidade de Évora: ensino e princípios. Da Europa para Évora e de Évora para o mundo: a Universidade Jesuítica de Évora (15591759). Maria de Fátima Nunes e Augusto da Silva (org). Chiado. Évora, 2009. 
A Universidade de Évora e a psicogênese da sociedade portuguesa em tempos de reforma católica

ELIAS, Norbert. O processo civilizador. Uma história dos costumes. Rio de Janeiro: Jorge Zahar, 1994a (v. 1).

ELIAS, Norbet. O processo civilizador. Formação do Estado e civilização. Rio de Janeiro: Jorge Zahar, $1994 \mathrm{~b}$ (v. 2).

ELIAS, Norbert. A sociedade dos indivíduos. Zahar. Rio de Janeiro: Jorge Zahar, 1994c.

ELIAS, Norbert; SCOTSON, John. Os estabelecidos e os outsiders: sociologia das relações de poder a partir de uma pequena comunidade. Rio de Janeiro: Jorge Zahar, 2000.

ELIAS, Norbert. Escritos e ensaios: Estado, processo, opinião pública. Rio de Janeiro: Jorge Zahar, 2006.

LEITE, Serafim. História da Companhia de Jesus no Brasil. Rio de Janeiro: Instituto Nacional do Livro, 1949 (Tomo VII).

MORAES, Antonio de. Diccionario da língua portuguesa. Typographia Lacérdina. Lisboa, 1813 (Tomo Segundo).

RATIO ATQUE INSTITUTIO STUDIORUM. Organização e plano de estudos da Companhia de Jesus. In: FRANCA, Leonel (org.). O método pedagógico dos jesuítas. Rio de Janeiro: Agir, 1952.

REYCEND, João Baptista. O sacrosanto, e ecumenico Concilio de Trento em latim e portuguez / dedica e consagra, aos... Arcebispos e Bispos da Igreja Lusitana, João Baptista Reycend. - Lisboa: na Off. de Francisco Luiz Ameno, 1781. Disponível em: http://purl. pt/360. Acesso em: 20 de ago. 2019.

SILVA, António Pereira da. Teologia moral em renovação. Lisboa: Didaskalia, 1971.

WREGE, Rachel Silveira. Os colégios da Companhia de Jesus e a criação do ensino superior: entraves, desafios e perspectivas. In: ENCONTRO DE PESQUISADORES; 14, 2013 , Franca (São Paulo): Uni-Facef, 2013 (v. 1). Disponível em: hitps://pos.unifacef.com. br/_livros/Vanguarda_Conhecimento/Artigos/Rachel_Wrege_3.pdf. Acesso em: 20 mar. 2020 . 
Profa. Dra. Cíntia Mara Bogo Bortolossi

Universidade Estadual de Maringá (Brasil)

Programa de Pós-Graduação em Educação

Grupo de Pesquisa: LEIP - Laboratório de Estudos do Império português Orcid id: https://orcid.org/0000-000 1-9145-606X

E-mail: cintia_bortolossi@hotmail.com

Prof. Dr. Célio Juvenal Costa

Universidade Estadual de Maringá (Brasil) Programa de Pós-Graduação em Educação Grupo de Pesquisa: LEIP - Laboratório de Estudos do Império português Orcid id: https://orcid.org/0000-0003-1226-7805

E-mail: celiojuvenalcosta@gmail.com

Recebido $1^{\circ}$ set. 2021

Aceito 18 nov. 2021 